\author{
Ewelina Butyńska \\ mgr inż. \\ Pracownia projektowa FASYS \\ MOSTY sp. z o.o. \\ e.butynska@gmail.com
}

DOI: 10.35117/A_ENG_16_08_05

\title{
Prognoses of traffic for the designed airport in Opole
}

\begin{abstract}
In the article, a prognoses of the air traffi $\mathrm{c}$ in the existing airport in Bydgoszcz has been performed. The infl uence of the number of inhabitants causing the air traffi $\mathrm{c}$ has been established. Based on the existing patterns, the optimistic and pessimistic prognoses has been performed. The prognosis for the airport in Bydgoszcz has been a base for the prognoses for the designed airport in Opole. The prognoses has been performed for the further calculations of the airfi eld elements in the designed airport in Opole. The article is based on the author's Master Thesis: Study of a fi eld plan for an airport, with tutor's assessment 5,0, in academic year 2015/2016.
\end{abstract}

Keywords: Prognoses of the air traffic; Airport; Air traffic

\section{Introduction}

According to the report including prognosis of the air traffic in Poland [2] on behalf of Ministry of Infrastructure, the prognosis of traffic in reference to the number of inhabitants of polish regions has been performed. The airport in Bydgoszcz has been considered and additionally the similar analysis has been done for the designed airport in Opole.

First, the location of the airports and the division of the passengers between them have been established. Taking that into account, the number of the passengers in the base year (2016) has been compared to the number of inhabitants considered in the region referring to the analysed airport. Next, the data of 2015 and 2015 years have been included and 2 additional scenarios (optimistic and pessimistic) have been added to create a pattern of increasing of the number of the passengers within the years. The target output of the prognosis are 3 stages (including one stage divided into optimistic and pessimistic scenarios):

- stage 1 - base year (2016),

- $\quad$ stage 2 - in 15 years (2031),

- $\quad$ stage $3 \mathrm{a}$ - in 30 years, pessimistic scenario (2046),

- stage $3 b$ - in 30 years, optimistic scenario (2046).

\section{Prognosis of urban density in polish provinces (years 2016-2046)}

Considering the data from Central Statistical Office projection [1], the prognosis of urban density in polish provinces has been performed. The results of the general analysis can be seen in the figure 1 Prognoses of the number of inhabitants in Poland for 30 years 


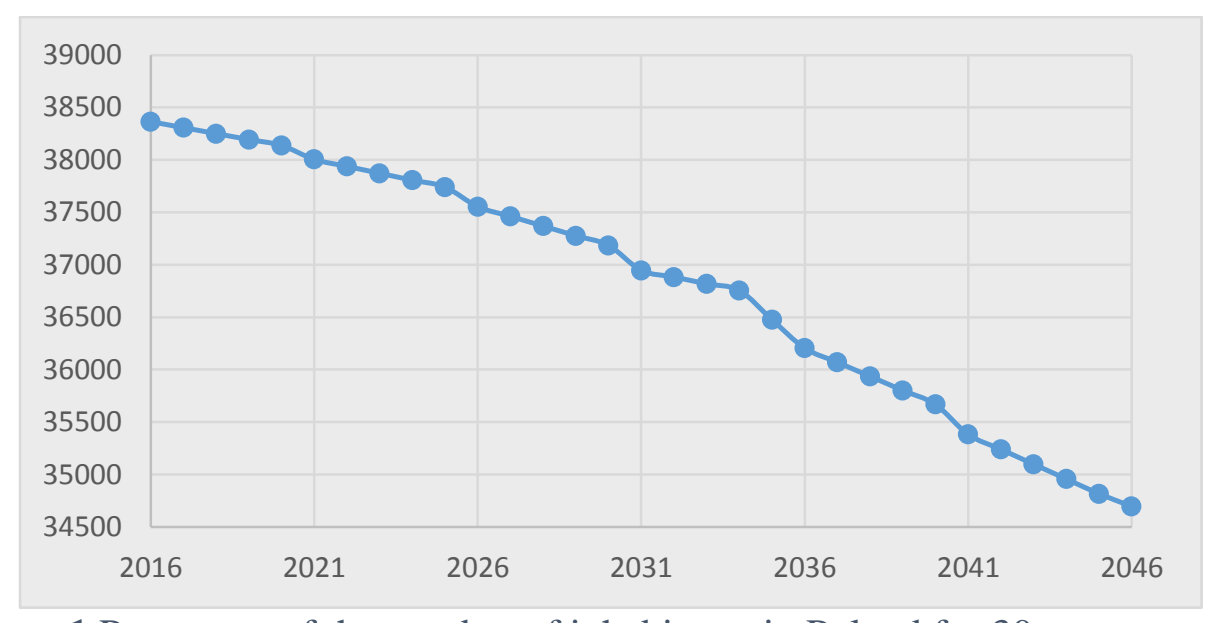

1 Prognoses of the number of inhabitants in Poland for 30 years

\section{Prognosis of the air traffic in the existing airport in Bydgoszcz}

\section{Scenario 0 - data from 2015}

The number of passengers for local traffic in Bydgoszcz is 736000 passengers/year and for international traffic - 679000 passengers/year. Considering the area that is covered by the airport (2 Division of air traffic for the airport in Bydgoszcz - Scenario 0 [2]), the number of inhabitants causing this traffic has been established by the formula (1).

where

$$
n=\sum_{i} x_{i} \cdot a_{i} \cdot b_{i}
$$

$x_{i}$ - part of the $i$ province being considered

$n$ - number of inhabitants generating the air traffic

$i$ - province included

$a_{i}$ - share of the air traffic for the $i$ province

$b_{i}$ - number of inhabitants in the $i$ province

For the following provinces the division is equal to:

- $[0,05 ; 0,1)$ for parts of provinces: zachodnio-pomorskie, wielkopolskie (assumed 0,1),

- $[0,1 ; 0,2)$ for part of province pomorskie (assumed 0,2),

- $[0,4 ; 0,5)$ for $1^{\text {st }}$ part of province kujawsko-pomorskie including Bydgoszcz city (assumed $0,5)$,

- $\quad[0,5 ; 0,75)$ for $2^{\text {nd }}$ part of province kujawsko-pomorskie (assumed 0,75).

Taking into account the division and number of inhabitants of the providences, number of inhabitants generating air traffic in Bydgoszcz is calculated from the formula (1) and it is equal to 1793 thousand inhabitants. 


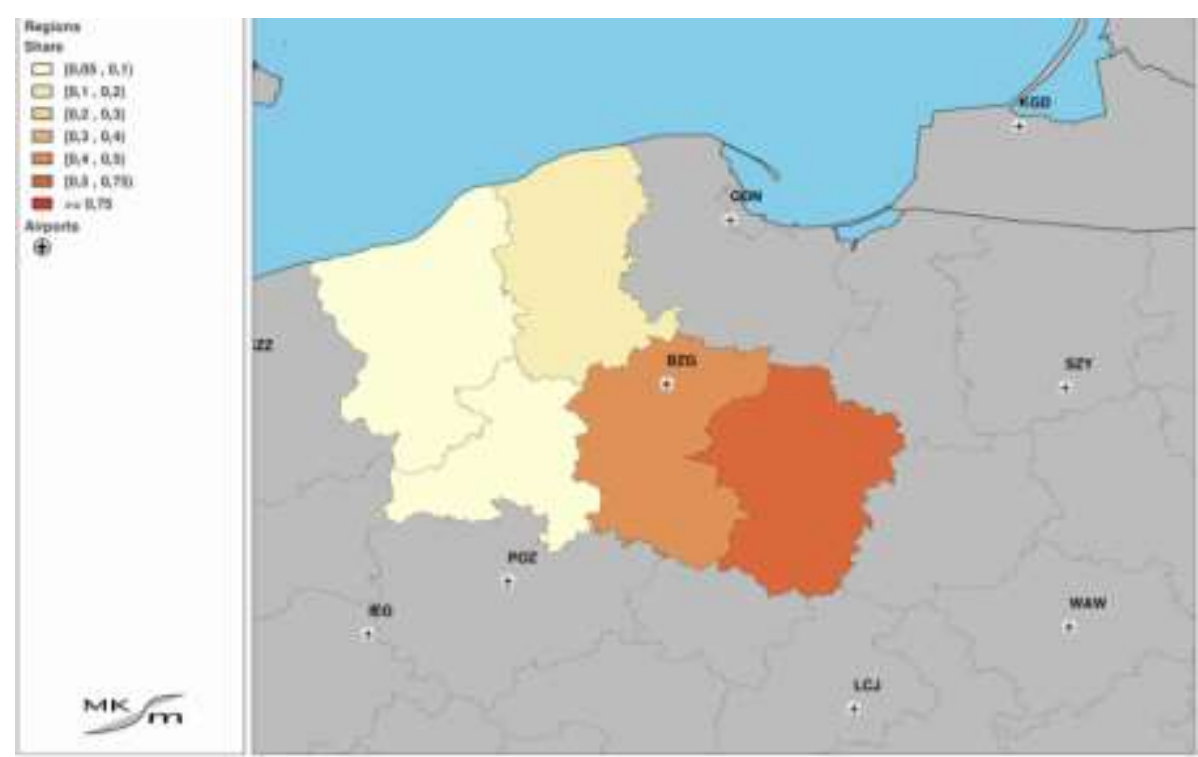

2 Division of air traffic for the airport in Bydgoszcz - Scenario 0 [2]

\section{Scenario 1 - data from 2025}

The number of passengers for local traffic in Bydgoszcz is 934000 passengers/year and for international traffic - 892000 passengers/year. Considering the area that is covered by the airport (3 Division of air traffic for the airport in Bydgoszcz - Scenario 1 [2]), the number of inhabitants causing this traffic has been established by the formula (1).

For the following provinces the division is equal to:

- $[0,1 ; 0,2)$ for part of province wielkopolskie (assumed 0,2),

- $[0,2 ; 0,3)$ for parts of provinces: zachodnio-pomorskie, pomorskie (assumed 0,3),

- $[0,5 ; 0,75)$ for province kujawsko-pomorskie (assumed 0,75).

Taking into account the division and number of inhabitants of the providences, number of inhabitants generating air traffic in Bydgoszcz is calculated with the formula (1) and it is equal to 2474 thousand inhabitants.

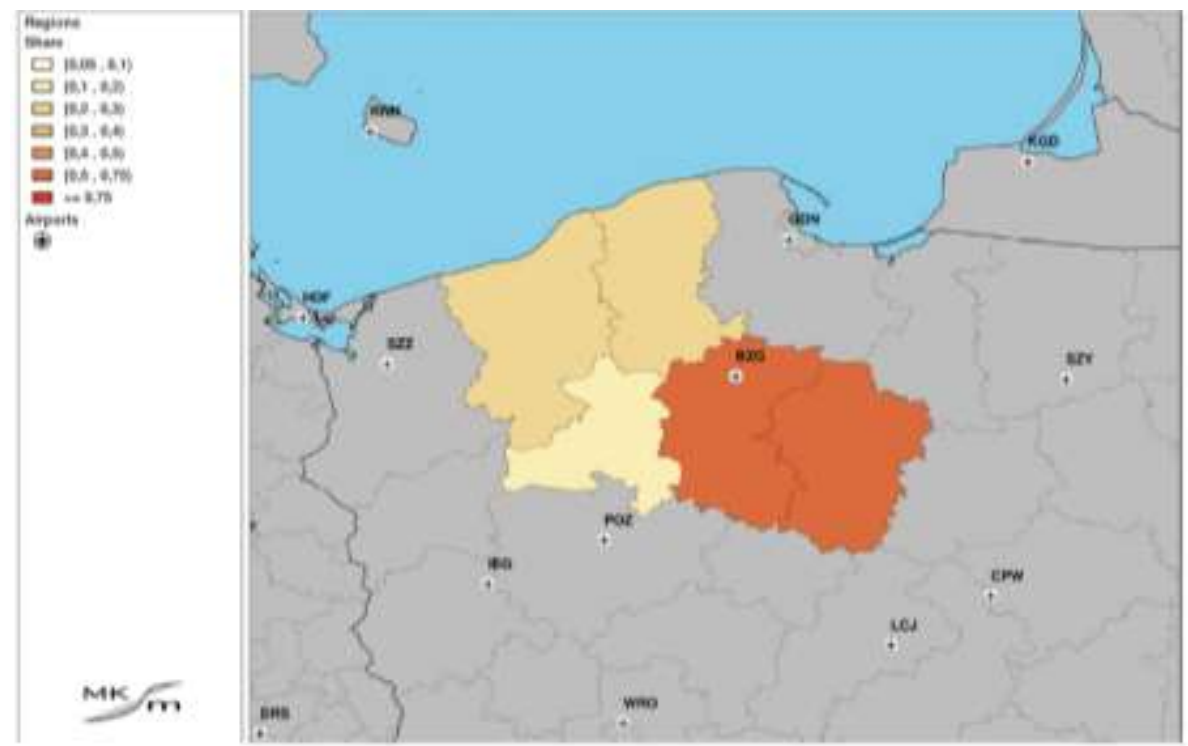

3 Division of air traffic for the airport in Bydgoszcz - Scenario 1 [2] 


\section{Scenario 2 (pessimistic) - data from 2035}

The number of passengers for local traffic in Bydgoszcz is 1259000 passengers/year and for international traffic - 1178000 passengers/year. Considering the area that is covered by the airport (4 Division of air traffic for the airport in Bydgoszcz - Scenario 2 [2]), the number of inhabitants causing this traffic has been established by the formula (1).

For the following provinces the division is equal to:

- $[0,05 ; 0,1)$ for part of province warmińsko-mazurskie (assumed 0,1),

- $[0,1 ; 0,2)$ for part of province wielkopolskie (assumed 0,2 ),

- $[0,3 ; 0,4)$ for parts of provinces: pomorskie, zachodnio-pomorskie (assumed 0,4),

- $[0,5 ; 0,75)$ for province kujawsko-pomorskie (assumed 0,75).

Taking into account the division and number of inhabitants of the providences, number of inhabitants generating air traffic in Bydgoszcz is calculated with the formula (1) and it is equal to 2688 thousand inhabitants.

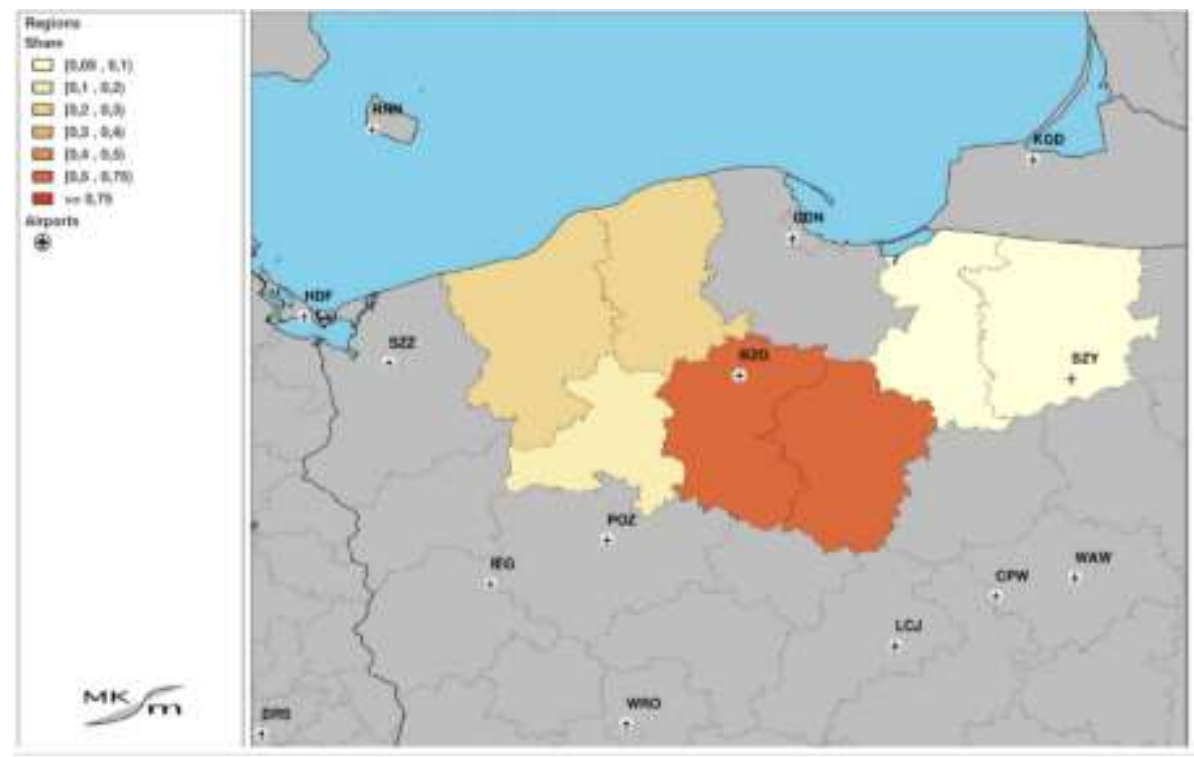

4 Division of air traffic for the airport in Bydgoszcz - Scenario 2 [2]

\section{Scenario 3 (optimistic) - data from 2035}

The number of passengers for local traffic in Bydgoszcz is 2280000 passengers/year and for international traffic -2167000 passengers/year. Considering the area that is covered by the airport (5 Division of air traffic for the airport in Bydgoszcz - Scenario 3 [2]), the number of inhabitants causing this traffic has been established by the formula (1).

For the following provinces the division is equal to:

- $[0,05 ; 0,1)$ for parts of province lubuskie (assumed 0,1 ),

- $[0,1 ; 0,2)$ for part of province: wielkopolskie, warmińsko-mazurskie (assumed 0,2),

- $[0,3 ; 0,4)$ for part of provinces: pomorskie, zachodnio-pomorskie (assumed 0,4),

- $[0,5 ; 0,75)$ for province kujawsko-pomorskie (assumed 0,75).

Taking into account the division and number of inhabitants of the providences, number of inhabitants generating air traffic in Bydgoszcz is calculated using the formula (1) and it is equal to 2829 thousand inhabitants. 


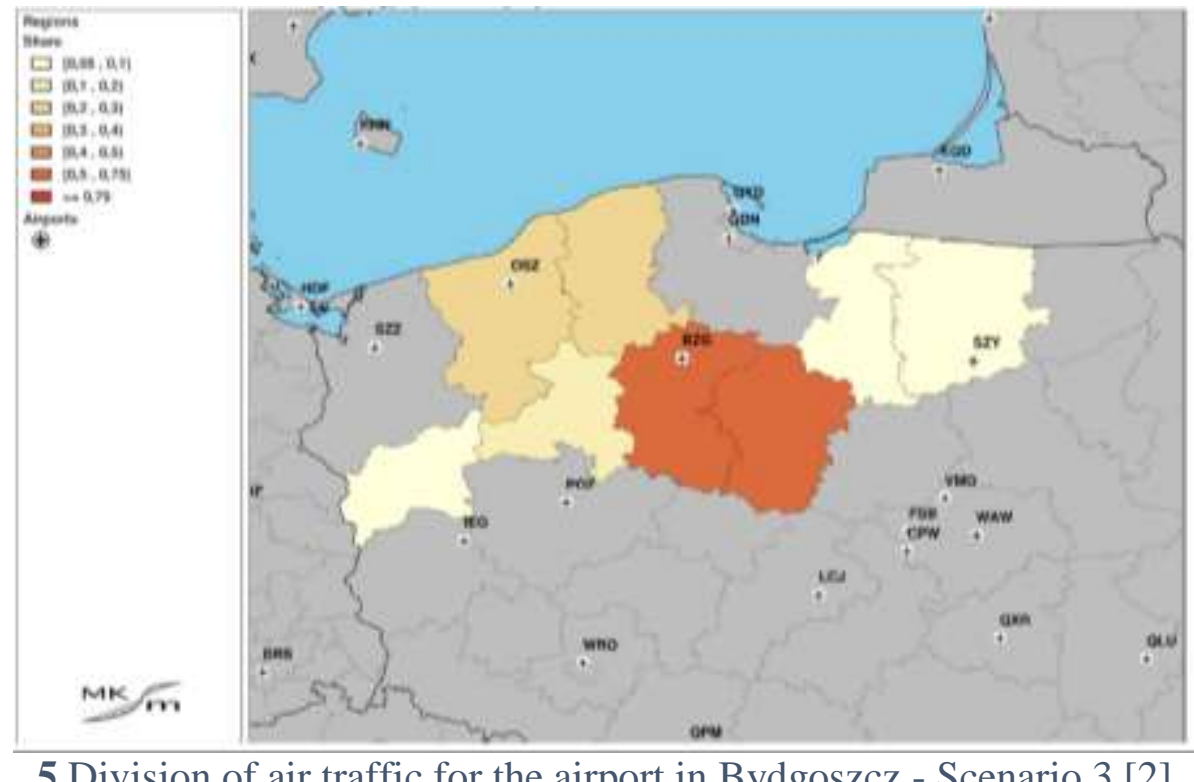

5 Division of air traffic for the airport in Bydgoszcz - Scenario 3 [2]

Prognosed number of inhabitants causing the air traffic in Bydgoszcz airport

Having calculated the number of inhabitants causing the air traffic in Bydgoszcz airport, the 30 -years prognosis has been performed in 2 scenarios - optimistic and pessimistic.

Increase of the number of inhabitants has been determined by the formulas (2) for an optimistic scenario and (3) for a pessimistic scenario.

where

$$
y=3215,57975-1,44946 \cdot 10^{60} \cdot 0,93693^{x},
$$

$x$ - year

$y$ - number of inhabitants in $\mathrm{x}$ year

where

$$
y=2786,06424-1,98493 \cdot 10^{104} \cdot 0,89069^{x}
$$

$x$ - year

$y$ - number of inhabitants in $x$ year

Having used the above formulas, the number of inhabitants for years 2016, 2031, 2046 have been determined. The results have been shown in Table 1 Prognosed number of inhabitants causing the air traffic.

Table 1 Prognosed number of inhabitants causing the air traffic

\begin{tabular}{|c|c|c|}
\hline \multirow{2}{*}{ Year } & \multicolumn{2}{|c|}{ Number of inhabitants } \\
\cline { 2 - 3 } & Optimistic scenario & Pessimistic scenario \\
\hline 2016 & 1889 & 1902 \\
\hline 2031 & 2716 & 2630 \\
\hline 2046 & 3028 & 2759 \\
\hline
\end{tabular}

Pessimistic prognosis for 2046 considering number of inhabitants

Having calculated the predicted number of inhabitants causing the air traffic and the number of passengers per year (Table 2 Number of passengers per year due to number of inhabitants for the pessimistic scenario), the diagram with predictions of the air traffic has been created ( 6 Number of passengers per year due to the number of inhabitants). 


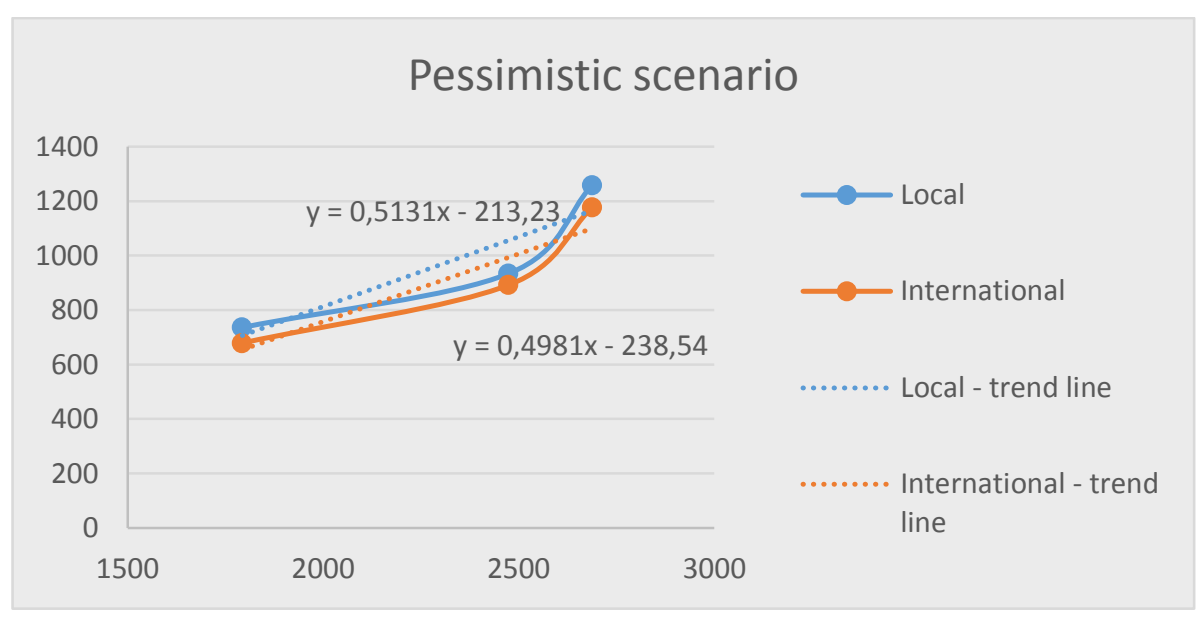

6 Number of passengers per year due to the number of inhabitants

The number of passengers has been determined by the formulas (4) for the local traffic and (5) for the international traffic and has been shown in Table 3 Number of passengers per year for 3 stages.

where:

$$
y_{L}=0,5131 x-213,23
$$

$y_{L}$ - number of local passengers per year [thousand]

$x$ - number of inhabitants [thousand]

$$
y_{I}=0,4981 x-238,54
$$

where:

$y_{I}-$ number of international passengers per year [thousand] $x$ - number of inhabitants [thousand]

\section{Optimistic prognosis for 2046 considering number of inhabitants}

Having calculated the predicted number of inhabitants causing air traffic and number of passengers per year(Table 4 Number of passengers per year due to number of inhabitants for the optimistic scenario), the pattern for the air traffic has been calculated.

The number of passengers has been determined by the formulas (6) for the local traffic and (7) for the international traffic.

where:

$$
y_{L}=1,3302 x-1289,7
$$

$y_{L}-$ number of local passengers per year [thousand]

$x$ - number of inhabitants [thousand]

where:

$$
y_{I}=1,2863 x-1796,6
$$

$y_{L}-$ number of international passengers per year [thousand]

$x$ - number of inhabitants [thousand]

Therefore, the number of passengers per year for the 3 stages has been shown in the Table 5 Number of passengers per year for 3 stages. 
Table 2 Number of passengers per year due to number of inhabitants for the pessimistic scenario

\begin{tabular}{|c|c|c|}
\hline \multicolumn{3}{|c|}{ Pessimistic scenario } \\
\hline \multirow{2}{*}{ No. of inhabitants } & Number of passengers [thousand passengers/year] \\
\cline { 2 - 3 } & Local & International \\
\hline 1793 & 736 & 679 \\
\hline 2474 & 934 & 892 \\
\hline 2688 & 1259 & 1178 \\
\hline
\end{tabular}

Table 3 Number of passengers per year for 3 stages

\begin{tabular}{|c|c|c|}
\hline \multirow{2}{*}{ Stage } & \multicolumn{2}{|c|}{$\begin{array}{c}\text { Number of passengers per year [thousand } \\
\text { passengers/year] }\end{array}$} \\
\cline { 2 - 3 } & Local traffic & International traffic \\
\hline Stage 1 & 763 & 709 \\
\hline Stage 2 & 1136 & 1071 \\
\hline Stage 3 & 1202 & 1136 \\
\hline
\end{tabular}

Table 4 Number of passengers per year due to number of inhabitants for the optimistic scenario

\begin{tabular}{|c|c|c|}
\hline \multicolumn{3}{|c|}{ Optimistic scenario } \\
\hline \multirow{2}{*}{ No. of inhabitants } & Number of passengers [thousand passengers/year] \\
\cline { 2 - 3 } & Local & International \\
\hline 1793 & 736 & 679 \\
\hline 2474 & 934 & 892 \\
\hline 2829 & 2280 & 2167 \\
\hline
\end{tabular}

Table 5 Number of passengers per year for 3 stages

\begin{tabular}{|c|c|c|}
\hline \multirow{2}{*}{ Stage } & \multicolumn{2}{|c|}{$\begin{array}{c}\text { Number of passengers per year [thousand } \\
\text { passengers/year] }\end{array}$} \\
\cline { 2 - 3 } & Local traffic & International traffic \\
\hline Stage 1 & 683 & 633 \\
\hline Stage 2 & 1783 & 1697 \\
\hline Stage 3 & 2198 & 2098 \\
\hline
\end{tabular}

\section{Prognosis of the air traffic in the designed airport in Opole}

Prognosis of the air traffic in the designed airport in Opole has been performed analogically to the prognosis for the airport in Bydgoszcz. First, the number of inhabitants causing this traffic has been established. Then, using this data, the prognosis for years 2016, 2031, 2046 has been performed. 
Considering the area that is covered by the airport ( 7 Division of air traffic for the airport in Opole [2]), the number of inhabitants causing this traffic has been established by the formula (1).

For the following provinces the division is equal to:

$[0,05 ; 0,1)$ for parts of provinces: łódzkie, śląskie (assumed 0,05 )

$[0,2 ; 0,3)$ for parts of provinces: dolnośląskie, wielkopolskie (assumed 0,3 )

$[0,5 ; 0,75)$ for province opolskie (assumed 0,50 in Scenarios 0,1,2 and 0,7 in Scenario 3).

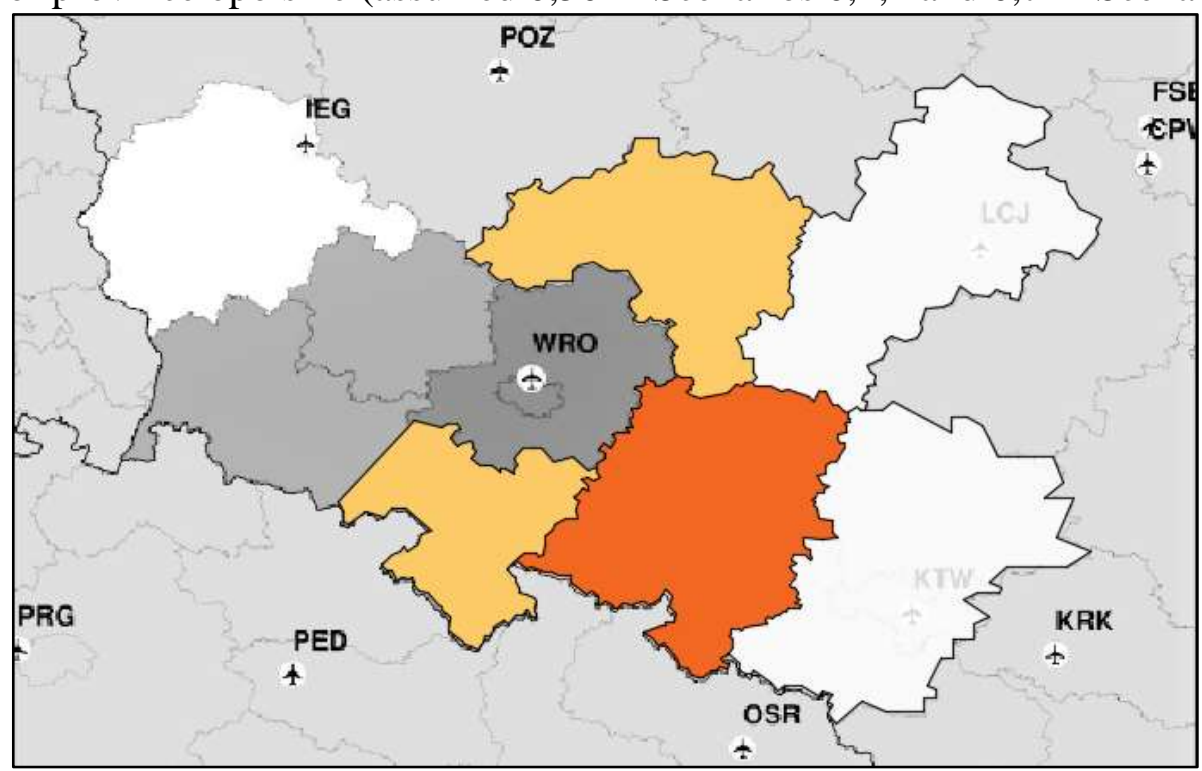

7 Division of air traffic for the airport in Opole [2]

\section{Scenario 0 - data from 2015}

For the following provinces the division is equal to:

$[0,05 ; 0,1)$ for parts of provinces: łódzkie, śląskie (assumed 0,05 )

$[0,3 ; 0,4)$ for parts of provinces: dolnośląskie, wielkopolskie (assumed 0,30 )

$[0,5 ; 0,75)$ for province opolskie (assumed 0,50 )

Taking into account the division and number of inhabitants of the providences, number of inhabitants generating air traffic in Opole is calculated using the formula (1).

$$
\begin{gathered}
n=0,5 \cdot 0,05 \cdot 2500+1 \cdot 0,05 \cdot 4579+0,25 \cdot 0,3 \cdot 2904+0,5 \cdot 0,3 \cdot 3467+1 \\
\cdot 0,5 \cdot 999=1382 \text { thousand inhabitants }
\end{gathered}
$$

\section{Scenario 1 - data from 2015}

For the following provinces the division is equal to:

$[0,05 ; 0,1)$ for parts of provinces: łódzkie, śląskie (assumed 0,05 )

$[0,3 ; 0,4)$ for parts of provinces: dolnośląskie, wielkopolskie (assumed 0,35 )

$[0,5 ; 0,75)$ for province opolskie (assumed 0,55 )

Taking into account the division and number of inhabitants of the providences, number of inhabitants generating air traffic in Opole is calculated using the formula (1).

$$
\begin{gathered}
n=0,5 \cdot 0,05 \cdot 2460+1 \cdot 0,05 \cdot 4506+0,25 \cdot 0,35 \cdot 2858+0,5 \cdot 0,35 \cdot 3412 \\
+1 \cdot 0,55 \cdot 983=1542 \text { thousand inhabitants }
\end{gathered}
$$

\section{Scenario 2 - data from 2025}

For the following provinces the division is equal to:

$[0,05 ; 0,1)$ for parts of provinces: łódzkie, śląskie (assumed 0,10 )

$[0,3 ; 0,4)$ for parts of provinces: dolnośląskie, wielkopolskie (assumed 0,35 )

$[0,5 ; 0,75)$ for province opolskie (assumed 0,60 ) 
Taking into account the division and number of inhabitants of the providences, number of inhabitants generating air traffic in Opole is calculated using the formula (1).

$$
\begin{gathered}
n=0,5 \cdot 0,1 \cdot 2392+1 \cdot 0,1 \cdot 4380+0,25 \cdot 0,35 \cdot 2778+0,5 \cdot 0,35 \cdot 3316+1 \\
\cdot 0,6 \cdot 956=1692 \text { thousand inhabitants }
\end{gathered}
$$

\section{Scenario 3 - data from 2035}

For the following provinces the division is equal to:

$[0,05 ; 0,1)$ for parts of provinces: łódzkie, śląskie (assumed 0,10 )

$[0,3 ; 0,4)$ for parts of provinces: dolnośląskie, wielkopolskie (assumed 0,40 )

$[0,5 ; 0,75)$ for province opolskie (assumed 0,70 )

Taking into account the division and number of inhabitants of the providences, number of inhabitants generating air traffic in Opole is calculated using the formula (1).

$$
\begin{gathered}
n=0,5 \cdot 0,1 \cdot 2392+1 \cdot 0,1 \cdot 4380+0,25 \cdot 0,4 \cdot 2778+0,5 \cdot 0,4 \cdot 3316+1 \cdot 0,7 \\
\cdot 956=1892 \text { thousand inhabitants }
\end{gathered}
$$

\section{Prognosed number of inhabitants causing the air traffic in Opole airport}

Having calculated the number of inhabitants causing the air traffic in Opole airport, the 30years prognosis has been performed in 2 scenarios - optimistic and pessimistic, the pattern for the air traffic prognoses has been created.

Increase of the number of inhabitants has been determined by the formulas (8) for the optimistic scenario and (9) for the pessimistic scenario.

where:

$$
y=51583 \ln (x)-391113
$$

$x$ - year

$y$ - number of inhabitants in $x$ year

where:

$$
y=31335 \ln (x)-237023
$$

$x$ - year

$y$ - number of inhabitants in $x$ year

Having used the above formulas, the number of inhabitants for years 2016, 2031, 2046 have been determined. The results have been shown in Table 6 Prognosed number of inhabitants causing the air traffic.

\section{Pessimistic prognosis for 2046 considering the number of inhabitants}

Having calculated the predicted number of inhabitants causing air traffic, the formulas (4) and (5) from Bydgoszcz airport calculations have been used to determine the number of passengers in local and international traffic.

Number of passengers has been determined for the local and for the international traffic. The results have been shown in Table 7 Number of passengers in 3 stages.

\section{Optimistic prognosis for 2046 considering the number of inhabitants}

Number of passengers has been determined by the formulas (6) for the local traffic and (7) for the international traffic. The results have been shown in Table 8 Number of passengers in 3 stages.

The final prognoses has been used for the further calculations of the airfield for the designed airport in Opole. 
Table 6 Prognosed number of inhabitants causing the air traffic

\begin{tabular}{|c|c|c|}
\hline \multirow{2}{*}{ Year } & \multicolumn{2}{|c|}{ Number of inhabitants } \\
\cline { 2 - 3 } & Optimistic scenario & Pessimistic scenario \\
\hline 2016 & 1375 & 1401 \\
\hline 2031 & 1758 & 1633 \\
\hline 2046 & 2137 & 1864 \\
\hline
\end{tabular}

Table 7 Number of passengers in 3 stages

\begin{tabular}{|c|c|c|}
\hline \multirow{2}{*}{ Stage } & \multicolumn{2}{|c|}{$\begin{array}{c}\text { Number of passengers per year [thousand } \\
\text { passengers/year] }\end{array}$} \\
\cline { 2 - 3 } & Local traffic & International traffic \\
\hline Stage 1 & 506 & 459 \\
\hline Stage 2 & 625 & 575 \\
\hline Stage 3a & 743 & 690 \\
\hline
\end{tabular}

Table 8 Number of passengers in 3 stages

\begin{tabular}{|c|c|c|}
\hline \multirow{2}{*}{ Stage } & \multicolumn{2}{|c|}{$\begin{array}{c}\text { Number of passengers per year [thousand } \\
\text { passengers/year] }\end{array}$} \\
\cline { 2 - 3 } & Local traffic & International traffic \\
\hline Stage 1 & 517 & 474 \\
\hline Stage 2 & 627 & 580 \\
\hline Stage 3b & 747 & 691 \\
\hline
\end{tabular}

\section{Source materials}

[1] Population projection 2014-2050, Central Statistical Office, Warsaw 2014

[2] Prognoza rozwoju transportu lotniczego w Polsce. Raport czastkowy z dn. 22. marca 2010r, MKmetric Gesellschaft für Systemplanung

[3] Author's Master Thesis: Study of a field plan for an airport, Supervisor: dr hab. inż. Maciej Kruszyna 